\title{
Study on Generation, Standardized Development and Risk Prevention Strategies of Overseas Purchase of Milk Powder
}

\author{
Jun Yan ${ }^{1}$, Hui Liu ${ }^{1}$ \\ ${ }^{1}$ Wuchang University of Technology, Wuhan, 430223, China
}

Keywords: Overseas purchase of milk powder; Standardized development; Risk prevention

\begin{abstract}
Although overseas purchase of milk powder is universal, it is not standardized. This paper starts from the reasons for abundant emergence of overseas purchase of milk powder in China, explores the present hidden dangers and risks of overseas purchase of milk powder on Chinese market and focuses on offer suggestions for the standardized development and risk prevention of overseas purchase of milk powder, such as standardizing the behavior subject for overseas purchase of milk powder, standardizing the tax collection and management for overseas purchase of milk powder, standardizing the sales channels for overseas purchase of milk powder and standardizing the regulation and inspection for overseas purchase of milk powder.
\end{abstract}

\section{Background for generating the upsurge of overseas purchase of milk powder and the current situation}

With the rapid development of economy, a large number of middle class emerged and people's consumption structure is largely changed; people's selection standard for product purchase is changed from the pattern dominated by cost performance to the pattern dominated by health and safety. Meanwhile, the Melamine Event, Big Head Kid Event and other events about the milk powder problems severely affected people's confidence in the safety and quality of homemade milk powder, so people desires for buying safer and more guaranteed overseas big-brand milk powder. But because the resources are limited, many families have no overseas relatives or friends who can help them buy overseas big-brand milk powder. On this background, there are large batches of overseas purchasing agents for milk powder and overseas purchases of overseas milk powder.

According to the Luxury Research Report of China for 2014, released by Bain \& Company, there was a negative growth in the luxury goods market in the mainland of China for the first time in 2014, with a reduction of $1 \%$ compared with 2013; but, correspondingly, the $9 \%$ of the expenditure of Chinese mainland consumers was increased in the global luxury market in 2014, reaching RMB 380 billion and accounting for about 30\% of the global luxuries. In 2014, our country imported 1.05 million tons of milk powder with a growth range of 6.5\%. Milk powder is one of the most hot-selling commodities purchased overseas among the most popular types of commodities purchased overseas.

\section{Standardized development and risk prevention strategies of overseas purchase of milk powder}

The main reason for people buying imported milk powder through overseas purchase is people's trust in the quality of imported milk powder and price advantage after tax avoidance compared with the selling price of imported milk powder in the supermarkets. But there are manly hidden dangers and risks in overseas purchase of milk powder due to its lack of standardization and absence of supervision. How to carry out standardized development and risk prevention for overseas purchase of milk powder is a problem which is extremely concerned about by people. We can make improvements through the several aspects below:

\section{To standardize the behavior subjects for overseas purchase of milk powder}

At present, the behavior subjects for overseas purchase of milk power, which are mainly the individuals who can go abroad and come back easily or who have overseas relations for providing overseas milk powder, purchase milk powder from abroad at low prices and then resell them on the domestic market at high prices by taking advantage of their own special identities or special resources, 
such as overseas students, workers abroad as well as those visiting their relatives abroad etc. Since the sales of commodities often gets involved in business tax, VAT tax and other fee and tax problems, such subjects are not standardized due to their lack of the qualification of subjects for selling milk powder; furthermore, they are not standardized because the overseas purchase and domestic sells of milk powder in large batches is inconsistent with the policies that protect local milk powder consumers through price limitation.

For example, Netherlands Government subsidizes the retailers of milk powder and synchronously strictly stipulates the sales and purchase of milk powder. At first, before fulfilling the purchase requirements of retailers, the milk powder agencies of Netherlands must confirm the sales terminals of retailers; besides, the retails only sell milk powders only in Netherlands, which means that individual purchasing agents cannot obtain the supply of milk power from the agencies due to their failure to satisfy the agencies' sales conditions. As a result, they can only obtain the supply in overseas supermarkets and stores as common consumers by studying or traveling abroad while they actually have no dealership for such milk powder in external markets. Furthermore, to obtain big profit difference, individual purchasing agents often purchase milk powders in large volumes when the milk powder is on sales promotion in holidays and festivals and then send them to China in batches. Since they buy milk power not for their own individual use but for profit purpose, the purchase belongs to the national scope of taxable items; at the same time, as the generally large volumes of purchase influence the local residents' normal use of milk powder, violating the local government's original intention for subsidizing milk powder and guaranteeing citizens' need, a series of home-purchase restrictions in allusion to Chinese people (Mainlanders) were formulated in many places. For example, there are English and Chinese signs on the milk powder shelves in many supermarkets and chain stores in Netherlands, indicating that customers cannot buy milk powder in large volumes or only two cans (or three cans) of milk powder can be purchased at most each time. Hong Kong Region even formulated the provisions for restrictive purchase of milk powder for mainlanders that those, who leave Hong Kong, are not allowed to take out any powdered formula for the infants under 36 months, including milk powder or soybean milk powder, without the license issued by the Director-General of the Trade and Industrial Department, for the purpose of guaranteeing the local Hong Kong dwellers' use need of milk powder.

To standardize the subjects for overseas purchase of milk powder, we can start with the definition of taxation subjects by adding the provisions on registration and management over taxes of network transactions to the existing tax registration system. Regardless of the differences, all the subjects of overseas purchase of milk powder will inevitably get involved in the problem of cross-boarder circulation of overseas milk powder, which can be solved in the ways below: someone brings the overseas milk powder to China directly through the customs or the milk circulation can be completed by international logistics through electronic commerce. Both of the ways must get involved with the problem of tax collection. If the first way is adopted, our following problem of tax collection will be involved. If the second way is adopted, the government can stipulate that taxpayers must handle the tax registration for electronic commerce at the competent tax authority to obtain the online tax registration number; then the tax authority will strictly inspect the relevant matters about overseas purchase applied by taxpayers and issue the online tax registration mark to standardize the subjects of overseas purchase of milk powder.

As a matter of fact, New Zealand canceled the home-purchase restrictions for milk powder by allowing some large-scale Chinese milk powder forwarders to upgrade and update their warehousing facilities at the end of 2012. They also went through all the procedures for export transportation of milk powder required by New Zealand Government. It is thus clear that, originally, New Zealand's home-purchase restriction for milk powder is not to restrict the export of dairy products but is to insist on the provisions of local laws that only registered exporters are eligible to export diary products. Online tax registration can legalize the subjects for purchase. The tax collection and management and policy subsidy can be implemented according to the taxpayer's declaration. For example, if the milk powder is sold locally, the subjects can enjoy the local government' s subsidies; if the milk power is 
sold overseas, the purchasing agents shall make up the difference in governmental subsidies and shall also pay taxes as per relevant provisions of the importing country at the same time.

The legalization of the subjects of overseas purchase of milk powder can not only avoid the risk of tax avoidance but also effectively guarantee the consumers' after-sales rights protection, largely reducing the risks incurred from different countries and long purchase time span.

\section{To standardize the tax collection and management for overseas purchase of milk powder}

Overseas purchases of milk powder have been growing swiftly over recent years. It is mainly because there are enormous profits in overseas purchase. If the cross-board circulation of milk powder is realized through transporting goods by customers or nothing-to-declare channel, there will be much more profits. For this reason, there are a lot of tax evasions or frauds due to the temptation of enormous profits. It was calculated that our tax erosion reached up to billions according to the transaction scale at RMB 48 billion for overseas purchase. Such lapsed taxes didn't benefit the final consumers but made their legal rights and interests unguaranteed due to the non-standardized channels. Thus, it is necessary to start from the angle of tax collection and management to standardize the overseas purchase of milk powder.

For the problem of tax collection and management for overseas purchase of milk powder, it is true that there are a series of influence factors causing difficulties in the implementation, such as the incorrect valuation, conflict with the application of law, concealed ways of bringing large volumes of milk power into China or tricky ways, but we are still able to maximally standardize it. At present, our country's stipulations on tax collection of overseas purchase of milk powder mostly rely on the limitation to the value amount of an entrant's belongings. In accordance with the provisions of relevant laws and regulations for departure and entry in our country, no luggage and postal article tax will be levied for the reasonable number of articles with the amount no more than RMB 5,000 brought by a Chinese citizen when entering into our country each time. It can be understood that the value of belongings when someone enters into China each time shall be calculated according to the times (of course, it is limited to the reasonable number for self-use), so, in principle, it is acceptable as long as the belongings one brings when entering into China comply with the reasonable number for self-use and the total amount does not exceed RMB 5,000. Although this provision can urge some purchasing agents to pay taxes, it fails to come into play for those who conveniently go abroad and come back because of studying abroad, working and other reasons. Such purchasing agents can completely evade taxes skillfully by going abroad repeatedly in a short time or by entrusting their friends to purchase dispersedly. The stewardess Li Xiaohang is an example like this. For this reason, the government can check the purchasing agents' time intervals for brining milk powder; the time interval for taking the amount of milk powder between the two times for entering the customs should be in a reasonable scope. If the amount is not within the reasonable scope, the inspectors are entitled to demand the person to rationally explain and prove it; or else, it is required to pay tax in strict accordance with the relevant provisions.

The strict tax collection and management can guarantee the overseas purchasing agents of milk powder for profit can enter into China through regular channels; meanwhile, the department concerned can also examine the quality, safety, nutrition and other aspects of overseas milk powder, which is about to flow into our country to guarantee the consumers' safety in use accordingly.

\section{To standardize the sales channels for overseas purchase of milk powder}

Acquaintances' overseas purchase and network overseas purchase are the principal channels for oversea purchase of milk powder. The former is a way of purchase that some acquaintances who often go abroad or stay abroad, such as the tour guide, stewardess, overseas student and employee abroad, who purchase commodities at overseas physical stores or on website and mail or personally carry them back to the demanders in China. Such way of purchase mainly appears among acquaintances and relatives and basically is not for making profits. However, the network overseas purchase is the service of purchasing overseas products for the buyers and gaining commission fees and other relevant fees based on network applications and international logistics. The pattern of network overseas purchase cover two service modes, B2C and C2C, namely, relying on the private 
C2C online stores (such as the overseas purchase stores of Taobao) on large shopping websites as well as the professional B2C purchase website (such as usashopcn.com and Yide.com). In the first pattern, because of the personal consideration between acquaintances relationship and the cross-boarder spatial distance, most consumers silently bear the losses without claiming for compensation if there is any loss; in the second pattern, due to the non-standardized network channels, many people sets up stores to offer overseas purchase of milk powder on the internet by paying low security deposit (for example, the security deposit at RMB 1,000 only is needed on Taobao.). But when there is any problem in the quality and safety of milk powder, they just cancel the online stores. Consequently, the consumers cannot find the online store owners to take responsibilities and it is even more difficult to seek compensations from overseas manufacturers.

As for the problem of non-standardized sales channels for overseas purchase of milk powder, the consumers should try to choose regular purchase websites to complete the overseas purchase of milk powder because of the more standardized process and relatively more guaranteed quality of goods. For example, "G.TAOBAO.COM" formulated distinctive restrictions for four types of retailers.

\section{To standardize the regulation and inspection for overseas purchase of milk powder}

Due to varied flowing paths and different sources of milk powder purchased overseas, relevant authorities cannot supervise or inspect such milk powder uniformly, resulting in production quality problem, packaging hygiene problem, incompliance of nutritional ingredients with national standards and other problems in the overseas milk powder flown in our country.

On one hand, because of low threshold of dairy industry and cheap raw materials in many countries, a lot of Chinese enterprises registered brands in those countries to hire OEM enterprises for listing production. Although the milk source of products manufactured by such small workshops are indeed imported abroad, their manufacturing technologies, safety and sanitation cannot be guaranteed; thus a lot of unqualified cheap overseas milk powder was produced.

On the other hand, considering the difference in the infants' constitution in each country, clear provisions on the content of vitamin and mineral substances have been formulated in each country. The infants' formula milk powder exported to China must comply with China's national standards, because the overseas milk powder sold abroad may not satisfy the growth and development needs of Chinese babies. The nutrient elements and microelements' nonconformity to Chinese standards is another key reason for inconformity of large volumes of overseas milk powder.

In view of this, the state must strictly control the milk powder to be imported and determine whether the milk powder conforms to Chinese infants' safety and nutrient needs mainly by checking the brand, place of production, product batch and other key information of milk powder. Only the milk powder which passes our country's relevant department inspection can be imported. It is also the same for the network purchase patter. If there is any new milk powder to be imported, application shall be submitted in advance and only the milk powder which passes the inspections can be imported. To standardize overseas purchase, the infants' formula milk powder which is not manufactured by an overseas registered manufacturer shall not be imported as of May 1, 2014, in accordance with the requirements of AQSIQ.

We cannot deny that the problem of overseas purchase of milk powder is because Chinese people's confidence crisis in domestic milk powder in the final analysis. If our domestic milk powder manufacturers are able to produce high-quality, cheap, safe and nutrient infant milk powder, the young mothers certainly will not take great pains to seek overseas purchase of milk powder at risk. To enhance the standard requirements for infant formula milk powder manufacturers' production and management licenses, quality and safety assurance, enterprise's responsibility as an entity etc., the China Food and Drug Administration formulated the Detailed Regulations on Production Permit of the Infant Formula Milk Powder (2013) in 2013. On May 30, 2014, the China Food and Drug Administration published the result of examination of production permit for infant milk powder as follows: 82 among 133 enterprises passed the examination and 51 "fails to pass it"; those without such license shall not get engaged in manufacturing the infant milk powder. The "new production permit for milk powder" was called the "strictest threshold in the history" in the industry. The 
implementation of this policy shows the state's determination to standardize the market of infant milk powder in our country. We also look forward to ADY, Ely and other milk powder brands' rising so that overseas purchase of milk powder will become the normal international circulation of common foods without the nearly discriminatory problems like restricted purchase.

\section{References}

[1] Lan Lan, Zhang Mengxiao. Exploration and Analyses on Taxation Law of Overseas Purchase Behaviors through Network - Establishing the Initial Imagination of “Overseas Purchase Tax”. Study on Tax Economy. 2012(5)

[2] Feng Kai. Analysis on Overseas Purchase Business through Network. Science Plaza. 2012(5)

[3] Cheng Siyao, Tian Minghua, Qiu Yang, Tian Haowei. Analyses on Development and Operation Mode of Overseas Purchase in Our Country. Northern Economy and Trade. 2012(1)

[4] Shen Sicheng, Jiang Zhuoran. Brief Discussion about Management over Early Warning Mechanism under Brand Crisis of "Credence Products" - Taking Diary Products as an Example. Journal of Jilin Provincial Institute of Education. 2012(8) 